\title{
A Study on the Influencing Factors of ASEAN Students' Willingness to Study in China and their Social Mentality Based on the Cases of Colleges in Guangxi
}

\author{
Huan Du ${ }^{1, a, ~ *}$ \\ ${ }^{1}$ Guangxi College of Sports and Physical Education, Nanning, Guangxi, China \\ a415098772@qq.com \\ ${ }^{*}$ Corresponding author
}

Keywords: ASEAN college students; Factors influencing the willingness to study in China; Social mentality.

\begin{abstract}
This survey is conducted in five universities in Guangxi with a total of 300 questionnaires distributed and 225 valid ones collected. It aims to analyze the factors influencing ASEAN students' willingness to study abroad, students' social mentality and the relationship between the two. The analysis leads to following findings: the local economic level, education equality, cultural and geopolitical background, policy support and bilateral relations influence the willingness of ASEAN students to study in China more or less, while the first three are the pivotal ones; ASEAN students' social mentality is favorable and positive overall; students' social mentality is significantly positively related to the influencing factors; students who are influenced by the factors more are likely to have a better social mentality. The improvement of the comprehensive strength of the country is beneficial to the cultivation of a good social mentality and the construction of a harmonious society.
\end{abstract}

\section{东盟国家大学生来华留学意愿影响因素与社会心态的相关研究 \\ 一以广西高校为例 \\ 杜欢 ${ }^{1, a, ~}{ }^{*}$ \\ 1广西体育高等专科学校, 南宁, 广西, 中国 \\ a415098772@qq.com \\ “通讯作者}

关键词：东盟留学生；来华留学影响因素；社会心态

中文摘要. 通过实证调查在广西五所高校进行科学抽样,共发放问卷300份, 回收有效问卷 225 份, 以此分析东盟学生的来华留学影响因素和社会心态, 并且探讨两者间的关系, 结果显示: 经济水平、教育水平、文化地缘关系、政策支持和双边关系在一定程度上影响东盟学生来华 留学意愿, 前三者的影响程度最高; 东盟留学生的社会心态整体正面、积极; 来华留学影响 因素与留学生社会心态呈显著正相关，受留学目的国经济水平、教育水平等各类因素影响程 度越高的学生, 社会心态越正面、积极。留学目的国综合实力的增强有利于培育留学生良好 的社会心态, 有助于和谐社会的建设。 


\section{1. 引言}

在教育国际化和“一带一路”倡议实施的背景下，来华留学人数快速增长，据广西新闻网 报道: “2017年境外来广西高校的长、短期留学生人数约为 14528 人, 其中东盟国家学生 9465 人，占比高达 $65 \%$ 。广西成为中国招收东盟国家留学生最多的省区之一" [1]。随着教育国际化 合作的持续升温, 有关外国学生来华留学影响因素的研究日益增多。总的来看, 国内学界主 要基于推拉理论、引力模型和社会文化新移民理论等几大理论来探讨留学生来华留学意愿影 响因素的问题。本文从社会心态的角度出发, 通过实证调查, 分析和探讨东盟留学生来华留 学意愿影响因素和社会心态的整体状况, 以及两者之间的相关性, 旨在探索高校留学生管理 的新策略, 为吸引国外优秀人才, 促进地区间文化交流, 推进共建“一带一路”民心相通工程 提供参考依据。

\section{2. 研究方法}

\section{1 研究对象}

本研究以在广西留学的东盟国家大学生为调查对象，在广西区内的五所高校进行随机抽 样, 抽样过程兼顾性别、年龄、教育水平等状况, 共发放问卷300份, 回收258份, 剔除无效 问卷 33 份, 最后有效问卷为 225 份。其中, 印度尼西亚（94人）、泰国（42人）、越南（35 人) 和老挝 (36人) 的留学生居多, 其余还包括马来西亚 (3人)、缅甸 (5人) 和柬埔寨 $(10$ 人) 的留学生。在性别构成上, 男性124人, 女性101人。

\section{2 研究工具}

本研究根据研究目的和内容, 以李克特五级量表为模型设计了两份量表, 从“非常不同意” 到“非常同意”分别计1到5分。

\subsection{1 《广西高校东盟学生来华留学意愿影响因素量表》}

经查阅文献发现，留学目的国经济水平、教育水平、文化及地缘关系、双边关系、留学 目的国政策支持等是影响留学生流向的主要因素。其中，杨军红从社会学角度出发，在推拉 理论的框架下考察留学生来华留学的影响因素, 发现国际社会留学潮的影响, 政治稳定、经

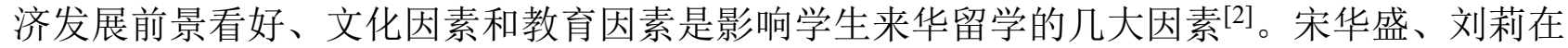
引力模型的基础上, 通过实证研究发现, 我国的经济水平和发展潜力、良好的双边贸易关系、 科技水平和教育水平改进、双边学历互认协议等是吸引留学生的主要因素, 而距离远、文化 差异大等因素对留学生来华产生了一定的负面影响 ${ }^{[3]}$ 。曲如晓等人基于文化认同的观点, 选 取承载中国传统文化内涵的文化产品贸易和来华旅游人数作为衡量指标, 发现文化认同对来 华留学生规模有显著影响 ${ }^{[4]}$ 。《广西高校东盟学生来华留学意愿影响因素量表》主要基于上 述影响因素从而构建指标进行设计, 单个题项得分越高表示对该题项涉及的影响因素的认可 度越高。经检验, 该量表的Cronbach $\alpha$ 系数为 0.723 。

\subsection{2 《广西高校东盟留学生社会心态量表》}

社会心态，从社会心理学角度考量，一般是指“在一段时间内弥散在整个社会或社会群体 /社会类别中的社会共识、社会情绪和感受, 以及社会价值取向”[5]。该量表主要是基于杨宜音 对“社会心态”的定义，在王俊秀构建的社会心态指标体系 ${ }^{[6]}$ 的基础上，结合留学生特征对指 标进行完善后编制。社会心态下设4个一级指标, 分别为: 社会认知、社会情绪、社会价值和 社会行为倾向, 因此共设置4份分量表。社会认知分量表包括社会安全感、社会支持感、社会 公正感和社会认同感4个维度; 社会情绪分量表包括对自身的情绪感知和对外界的情绪感知 2 个维度; 社会价值分量表包括文化观、人际观和消费观 3 个维度; 社会行为倾向分量表包括矛 盾化解策略、公共参与行为倾向和公共道德行为倾向 3 个维度。单个项目得分越高, 表示评价 
越高。经检验, 各分量表的Cronbach $\alpha$ 系数在 $0.679 \sim 0.710$ 之间, 各维度的Cronbach $\alpha$ 系数在 $0.423 \sim 0.810$ 之间。

\section{3. 研究结果}

\section{1 东盟学生来华留学意愿影响因素总体状况}

东盟留学生来华学习影响因素总均分及各维度上项目均分都超过 3 分, 其中经济水平得分 最高, 双边关系得分相对较低。由结果得知, 经济水平对东盟学生选择来华留学影响最大, 双边关系影响相对较小。

表1＼cjkstart东盟学生来华留学意愿影响因素状况

\begin{tabular}{|c|c|c|c|c|c|c|}
\hline & $\begin{array}{c}\text { 来华留学 } \\
\text { 意愿 }\end{array}$ & 经济水平 & 教育水平 & 政策支持 & $\begin{array}{c}\text { 文化地缘 } \\
\text { 关系 }\end{array}$ & 双边关系 \\
\hline $\mathrm{M}$ & 3.60 & 4.13 & 3.57 & 3.38 & 3.67 & 3.27 \\
\hline $\mathrm{SD}$ & 0.43 & 0.5 & 0.59 & 0.73 & 0.65 & 1 \\
\hline
\end{tabular}

\section{2 东盟来华留学生社会心态总体状况}

分析得知, 东盟来华留学生在社会心态各一级指标和二级指标的总均分都超过了 3 分, 大 部分接近4分。其中, 社会价值分问卷的均分最高, 社会情绪的分问卷均分最低。结果说明, 东盟来华留学生的社会心态总体良好、正面和积极。

表2＼cjkstart东盟来华留学生社会心态现状

\begin{tabular}{|c|c|c|c|c|c|c|c|c|}
\hline & $\begin{array}{c}\text { 社会 } \\
\text { 认知 }\end{array}$ & $\begin{array}{c}\text { 社会 } \\
\text { 安全感 }\end{array}$ & $\begin{array}{c}\text { 社会 } \\
\text { 支持感 }\end{array}$ & $\begin{array}{c}\text { 社会 } \\
\text { 公正感 }\end{array}$ & $\begin{array}{c}\text { 社会 } \\
\text { 认同感 }\end{array}$ & $\begin{array}{c}\text { 社会 } \\
\text { 情绪 }\end{array}$ & $\begin{array}{c}\text { 对自身的 } \\
\text { 情绪感知 }\end{array}$ & $\begin{array}{c}\text { 对外界的 } \\
\text { 情绪感知 }\end{array}$ \\
\hline $\mathrm{M}$ & 3.67 & 3.82 & 3.33 & 3.68 & 3.85 & 3.3 & 3.08 & 3.66 \\
\hline $\mathrm{SD}$ & 0.39 & 0.5 & 0.76 & 0.49 & 0.54 & 0.52 & 0.74 & 0.61 \\
\hline $\mathrm{M}$ & $\begin{array}{c}\text { 社会 } \\
\text { 价值 }\end{array}$ & 文化观 & 人际观 & 消费观 & $\begin{array}{c}\text { 社会行为 } \\
\text { 倾向 }\end{array}$ & $\begin{array}{c}\text { 矛盾化解 } \\
\text { 策略 }\end{array}$ & $\begin{array}{c}\text { 公共参与 } \\
\text { 行为倾向 }\end{array}$ & $\begin{array}{c}\text { 公共道德 } \\
\text { 行为倾向 }\end{array}$ \\
\hline $\mathrm{SD}$ & 3.76 & 3.6 & 3.62 & 4.28 & 3.63 & 3.62 & 3.74 & 3.49 \\
\hline
\end{tabular}

\section{3 高、低留学意愿的东盟学生社会心态比较}

为探究受各类因素影响程度不同的来华留学生在社会心态上是否有差异, 将 255 名东盟留 学生来华留学意愿影响因素总体得分由高到低进行排序, 得分在前 $30 \%$ 的学生为高分组即高 留学意愿组, 得分在后 $30 \%$ 的学生为低分组即低留学意愿组, 从而比较两组差异。

\section{表3＼cjkstart高、低留学意愿东盟学生社会心态差异比较}

\begin{tabular}{|c|c|c|c|c|}
\hline & 社会认知 & 社会情绪 & 社会价值 & 社会行为倾向 \\
\hline 高留学意愿组 & $3.810 \pm 0.329$ & $3.346 \pm 0.530$ & $3.876 \pm 0.405$ & $3.723 \pm 0.453$ \\
\hline 低留学意愿组 & $3.505 \pm 0.449$ & $3.171 \pm 0.526$ & $3.665 \pm 0.465$ & $3.476 \pm 0.476$ \\
\hline
\end{tabular}

结果显示, 高留学意愿组留学生的社会心态在各个维度上的得分均高于低留学意愿组, 说明受留学目的国经济水平、教育水平、政策支持、文化地缘关系和双边关系影响程度越高 的东盟留学生, 社会心态越正面、积极。

\section{4. 来华留学意愿影响因素与社会心态相关分析}

结果显示, 东盟留学生来华留学意愿与社会心态在总分和各维度上均呈显著正向相关, 说明越认可中国的经济发展水平、教育质量、教育政策, 喜欢相近的地理环境与社会文化的 东盟学生, 社会心态越正面、积极。 
表4 东盟学生来华留学意愿影响因素与社会心态相关性检验结果

\begin{tabular}{|c|c|c|c|c|c|c|}
\hline & $\begin{array}{c}\text { 来华留学 } \\
\text { 意愿 }\end{array}$ & 经济水平 & 教育水平 & 政策支持 & $\begin{array}{c}\text { 文化地缘 } \\
\text { 关系 }\end{array}$ & 双边关系 \\
\hline 社会心态 & $0.371 * *$ & $0.330^{* *}$ & $0.435 * *$ & $0.248 * *$ & $0.162 *$ & $0.023^{*}$ \\
\hline 社会认知 & $0.483^{* *}$ & $0.237 * *$ & $0.469 * *$ & $0.307^{* *}$ & $0.310^{* *}$ & $0.155^{*}$ \\
\hline 社会情绪 & $0.130 *$ & $0.155^{*}$ & $0.076^{*}$ & 0.086 & $0.217 * *$ & $0.251 * *$ \\
\hline 社会价值 & $0.350 * *$ & $0.271 * *$ & $0.304 * *$ & $0.249 * *$ & $0.272 * *$ & $0.039 *$ \\
\hline $\begin{array}{c}\text { 社会行为 } \\
\text { 倾向 }\end{array}$ & $0.355^{* *}$ & $0.198^{* *}$ & $0.328 * *$ & $0.239 * *$ & $0.149^{*}$ & $0.189^{* *}$ \\
\hline
\end{tabular}

（注：*表示 $\mathrm{p}<0.05 ， * *$ 表示 $\mathrm{p}<0.01[$ 双侧]）

\section{5. 分析讨论}

\section{1 东盟学生来华留学意愿影响因素总体状况分析}

研究发现, 留学目的国的经济水平、教育水平、政策支持、文化地缘关系以及留学派遣 国和目的国的双边关系等因素均会直接影响东盟学生选择来华留学的意愿。其中，最重要的 影响因素是目的国的经济实力，其次是文化地缘关系、教育水平、政策支持和双边关系。在 中国一一东盟区域经济一体化进程加快, “一带一路”倡议深入发展, 中国经济实力不断增强 的背景下, 东盟学生看好中国发展前景, 良好的经济环境能够为留学生提供优越的生活环境、 优秀的教育资源以及可观的发展前景。文化地缘关系方面, 中国与东盟国家山水相连, 便利 的交通方便东盟留学生往返家乡和学校, 相近的文化习俗也使得东盟学生更容易克服跨文化 影响从而融入当地社会。在政策支持上, 中央和地方政府逐年加大对来华留学教育的支持, 设立来华留学奖学金等举措成为吸引众多东盟学生来华留学的重要影响因素。此外, 中国的 教育实力和水平也是影响东盟学生来华留学意愿的主要因素, 中国与东盟各国间的关系以互 惠合作、睦邻友好、发展共赢为主流, 因此, 东盟学生在选择来华留学时对双边关系的考量 相对较少。

\section{2 东盟来华留学生社会心态总体状况分析}

研究发现，东盟来华留学生社会心态总体得分处于中等偏上水平，整体呈现正面、积极、 良好的状态, 说明在华学习的东盟留学生较认可中国的社会环境、社会文化、人际关系、社 会价值观等, 愿意主动融入当地社会生活, 参与到当地社会活动中。

\section{3 东盟留学生来华留学意愿影响因素与社会心态关系分析}

研究发现, 东盟留学生来华留学意愿影响因素与社会心态关系密切, 并且呈现正向相关。 综合高意愿组和低意愿组的对比分析, 以及来华留学意愿影响因素与社会心态的相关性分析 结果得知, 受留学目的国经济水平、文化地缘关系、教育水平、政策支持等因素影响程度越 高的留学生, 他们的社会心态越正面、积极。我国经济实力增强, 教育质量提升, 出台面向 留学生的利好政策等有利于提升留学生对我国社会的认可度, 在这样的环境下生活学习, 他 们感到安全, 得到认同, 获得支持, 喜爱当地文化, 愿意把自己当作当地社会的一份子, 参 与社会活动, 履行社会责任, 有利于建设社会主义和谐社会。反之, 培育留学生良好、积极、 正能量的社会心态能够坚定他们在中国学习生活的意愿和信心，从而吸引更多留学生知华友 华亲华爱华，参与到中国社会的宏伟建设中。

\section{致谢}

本文为广西体育高等专科学校2017年度科研重点项目《国际教育合作背景下的东盟国家 来桂留学生社会心态研究》（项目编号：tzkyzd201701）的阶段性成果之一。 


\section{References}

[1] China News Network. The 3rd China-ASEAN Higher Education Cooperation Forum was held in Nanning. 2018.11.10. www.chinanews.com/wap/detail/zw/cul/2018/11-10/8673636.shtml

[2] Qu Ruxiao, Li Jing, Yang Xiu. The influence of cultural identity on the size of international students in China. Economic latitude, Vol. 33(03), pp. 48-53, 2016.

[3] Song Hua Sheng, Liu Li. Why foreign students come to China to study abroad_-An empirical study based on gravity model. Higher Education Research, Vol. 11, pp. 31-38, 2014.

[4] Yang Junhong. Analysis of the characteristics and influencing factors of foreign students in China. Journal of South-Central University for Nationalities (Humanities and Social Sciences Edition), Vol. S1, pp. 103-107, 2006.

[5] Yang Yiyin. Psychological relationship between individual and macro society: Definition of social mentality concept. Sociological Research, Vol. 4, pp. 117-131+244, 2006.

[6] Wang Junxiu. The structure and indicator system of social mentality. Social Science Front, Vol. 2, pp. 163-173, 2013. 